\title{
EFFECTS OF TEMPERATURE AND SALINITY ON THE DECAPSULATION OF ARTEMIA CYST
}

\author{
Md. Kamrul Hasan and Md. Golam Rabbane* \\ Department of Fisheries, University of Dhaka, Dhaka-1000, Bangladesh
}

\begin{abstract}
A study was performed to determine to effect of salinities $(20,25,28$, $30,32,35$ and $40 \mathrm{ppt})$ and temperatures $\left(20,24,28,30\right.$ and $\left.32^{\circ} \mathrm{C}\right)$ on the decapsulation of Artemia cyst. The dry Artemia cyst were hydrated up to $2 \mathrm{hrs}$ in fresh water at $\left(26 \pm 1^{\circ} \mathrm{C}\right)$ temperature with a density $0.3 \mathrm{~g} / 50 \mathrm{ml}$ water. Saline water was prepared using salt $(\mathrm{NaCl})$ and hatching rate of Artemia cyst was counted after 36 hours of incubation. Highest hatching rate (72.59 \pm 5.03$),(75.84$ \pm 3.67), (74.45 \pm 0.83$),(89.38 \pm 0.96),(76.46 \pm 4.63),(70.58 \pm 9.51)$ and $(69.17 \pm$ 0.70 )\% were observed in $20,25,28,30,32,35$ and 40 ppt salinities at $32,28,28$, $24,24,24$, and $28^{\circ} \mathrm{C}$ temperature, respectively. Lowest hatching rate (57.03 \pm 3.67), (47.97 \pm 8.06), (46.20 \pm 8.17$),(39.58 \pm 10.12),(47.36 \pm 7.04)(25.86 \pm 8.10)$ and $(20.57 \pm 2.71) \%$ were measured in $20,25,28,30,32,35$ and 40 ppt salinities at $30,32,32,32,32,32$ and $32^{\circ} \mathrm{C}$, respectively. The maximum hatching rate $(89.38 \pm 0.96) \%$ was found in $30 \mathrm{ppt}$ salinity at $24^{\circ} \mathrm{C}$ temperature and minimum hatching rate $(20.57 \pm 2.71) \%$ was observed in 40 ppt salinity at $32^{\circ} \mathrm{C}$ temperature. Therefore, $30 \mathrm{ppt}$ salinity and $24^{\circ} \mathrm{C}$ temperature could be the optimum salinity-temperature for Artemia cyst decapsulation.
\end{abstract}

Key words: Temperature, salinity, decapsulation, Artemia

\section{INTRODUCTION}

Artemia is a crustacean live food item distributed all over the world including tropical, subtropical and temperate zones. It is widely used as live food for larvae of finfish and shellfish especially Macrobrachium rosenbergii (De Man 1879) and Penaeus monodon (Fabricius 1798) (Lavens and Sorgeloos 1996, Triantaphyllidis et al. 1998, Lavens et al. 1986). Every year more than 2000 metric ton Artemia cyst are marketed all over the world for aquaculture production purposes. The demand of Artemia cyst is increasing day by day in aquaculture industry and it comprises almost $40 \%$ of total larval food in aquaculture production (Sorgeloos et al. 2001).

In Bangladesh, Artemia cyst are used in a large scale specially in shrimp and prawn hatchery due to its higher nutritional value and ease of uses (Naser et al. 2016). Generally Artemia cyst are imported from different countries like USA, China, Brazil etc. and cyst are decpsulated in the hatchery. The decapsulation rate of Artemia cyst greatly depends on the salinity, temperature, aeration and

*Author for correspondence: <rabbane@du.ac.bd>

(c) 2018 Zoological Society of Bangladesh DOI: http://dx.doi.org/10.3329/bjz.v46i2.39053 
$\mathrm{pH}$ of water (Ahmed et al. 1997, Lavens and Sorgeloos 1996). A small number of works has been conducted to observe the effect of salinity and temperature on the decapsulation of cyst (Ahmed et al. 1997, Sharahi and Zarei 2016). But, there was lack of research work of precise temperature and salinity or their combined effect on cyst decapsulation. That is why, an experiment was conducted to find out the influence of salinity and temperature on the decapsulation of cyst.

\section{MATERIAL AND METHODS}

Artemia cyst was purchased from the local market shops at Kataban, Nilkhet, Dhaka, Bangladesh. The origin of the cyst was GSL (Great Salt Lake), USA. Artemia cyst is protected by a hard shell that encysts the dormant Artemia embryo. This Artemia embryo was completely removed from the cyst by a short term incubation in saline solution with aeration. This procedure is called decapsulation of cyst (Lavens and Sorgeloos 1996). Total three stages involved in decapsulation procedures.

The first step of decapsulation procedure was hydration of Artemia cyst. Hydration of cysts allowed for separation of the nauplii from the chorion, facilitating the decapsulation process. For this purpose, Artemia cysts were kept in a beaker with fresh water at room temperature for approximately two hour, using a concentration of $0.25 \mathrm{~g}$ of cysts per $50 \mathrm{ml}$ of water (Sorgeloos and Skujlasekarapandian 1984). The hydration procedure was maintained at $26 \pm$ $1{ }^{\circ} \mathrm{C}$ temperature. The second step of decapsulation was removal of live embryo in saline solution from its brown shell. For this purpose, decapsulation solution was prepared using $500 \mathrm{ml}$ of water in a beaker with iodine free salt. The amount of salt was calculated using following formula:

The amount of salt needed $(g)=\frac{\text { Desired salinity }(p p t) \times 500}{1000}$

Seven types of decapsulation salinity solution were prepared (e.g. 20, 25, 28, $30,32,35$ and $40 \mathrm{ppt}$ ). Three replicates were maintained for each treatment. Decapsulation was performed at $20,24,28,30$ and $32^{\circ} \mathrm{C}$ temperatures. Temperature and salinity of water were checked using a Handheld Salinity, Conductivity \& Temperature meter (YIS 30, USA).

During the decapsulation of Artemia cyst, continuous aeration was offered in each beaker for proper hatching of embryo. For this porpose, aerator (SB-348A air pump) was used. $\mathrm{pH}$ of decapsulation solution was maintained at 8.0 to 8.5. 
Hatching rate of the decapsulated cyst was observed after 36 hours of aeration. Hatching rate was calculated using following formula (Sorgeloos and Skujlasekarapandian 1984):

$$
\text { Hatching rate }(\%)=\frac{\text { Number of hatched embryo } \times 100}{\text { No. of hatched embryo /No. of unhatched embryo }}
$$

The hatching rate data obtained from the study were analyzed statistically using statistical software (SPSS, version 16.0, SPSS Inc., Chicago, USA). One way ANOVA and multiple camparison test (Tukey HSD post hoc test) was used to compare different hatching rate at different temperatures. All data were presented with mean \pm standard error (SE).

\section{RESULTS AND DISCUSSION}

The effect of temperature on decapsulation of Artemia cyst at 20 ppt salinity is presented in Fig. 1. Highest hatching rate $(72.59 \pm 5.03 \%)$ was observed in $32^{\circ} \mathrm{C}$ temperature at $20 \mathrm{ppt}$ salinity. Lowest hatching rate $(57.03 \pm 3.67 \%)$ was found in $30^{\circ} \mathrm{C}$ temperature at $20 \mathrm{ppt}$ salinity. But there is no significance difference $(\mathrm{p}>0.05)$ among $20,24,28,30$ and $32^{\circ} \mathrm{C}$ temperature.

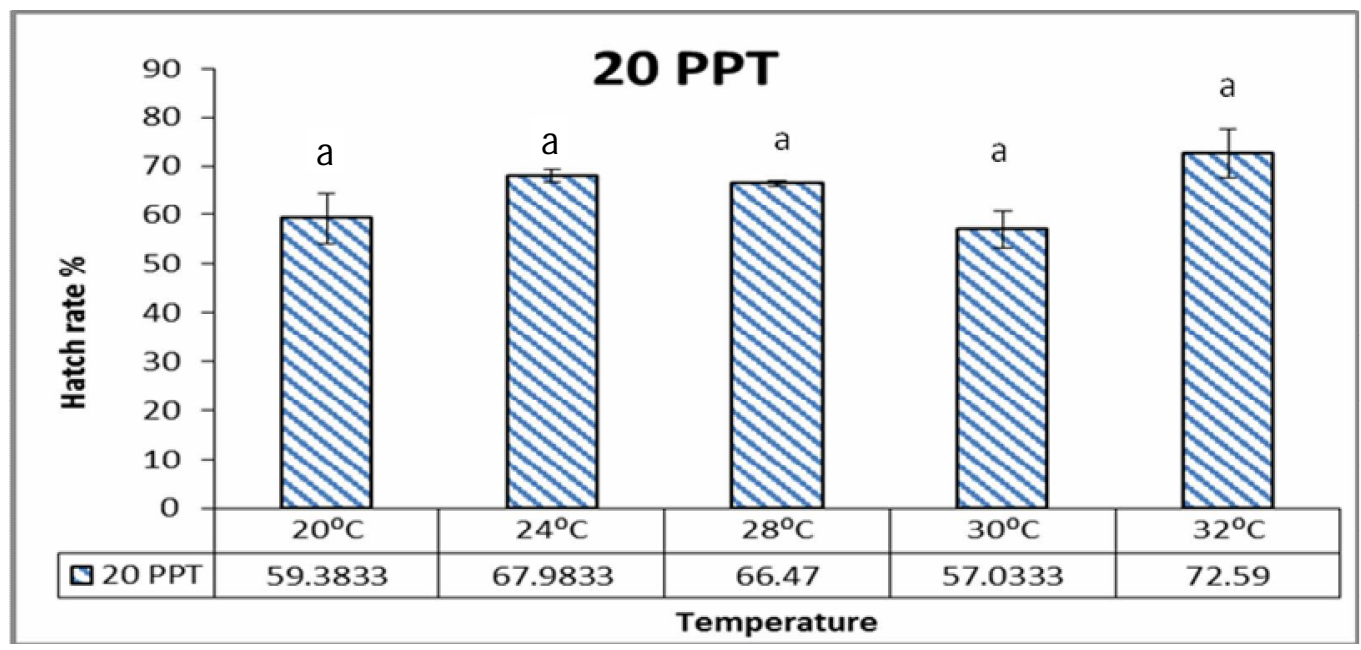

Fig. 1. Effect of temperature on decapsulation of Artemia cyst at $20 \mathrm{ppt}$ salinity. Values are mean \pm SEM. Bar with similar letter designated no significantly difference ( $p>0.05$, analyzed by one way ANOVA and Tukey`s test).

Ahmed et al. (1997) performed an experiment on the effect of decapsulation on viability and hatching of Artemia cysts at different salinities. They found highest hatching rate $(75.7 \pm 2.5 \%)$ and lowest $(70.0 \pm 1.7 \%)$ at $20 \mathrm{ppt}$ 
salinity after $36 \mathrm{hrs}$ of incubation. So the highest hatching rate is similar to this study but lowest hatching rate could be due to the low temperature $\left(20^{\circ} \mathrm{C}\right)$.

Significantly highest hatching rate was found $75.84 \pm 3.67 \%$ in $28^{\circ} \mathrm{C}$ temperature and lowest hatching rate $47.97 \pm 8.06 \%$ in $32^{\circ} \mathrm{C}$ temperature at 25 ppt when compare with among $20,24,28,30$ and $32^{\circ} \mathrm{C}$ temperature (Fig. 2). There was significant difference among 24,28 and $32^{\circ} \mathrm{C}$ and no significant differences were observed among 20,30 and $32^{\circ} \mathrm{C}$.

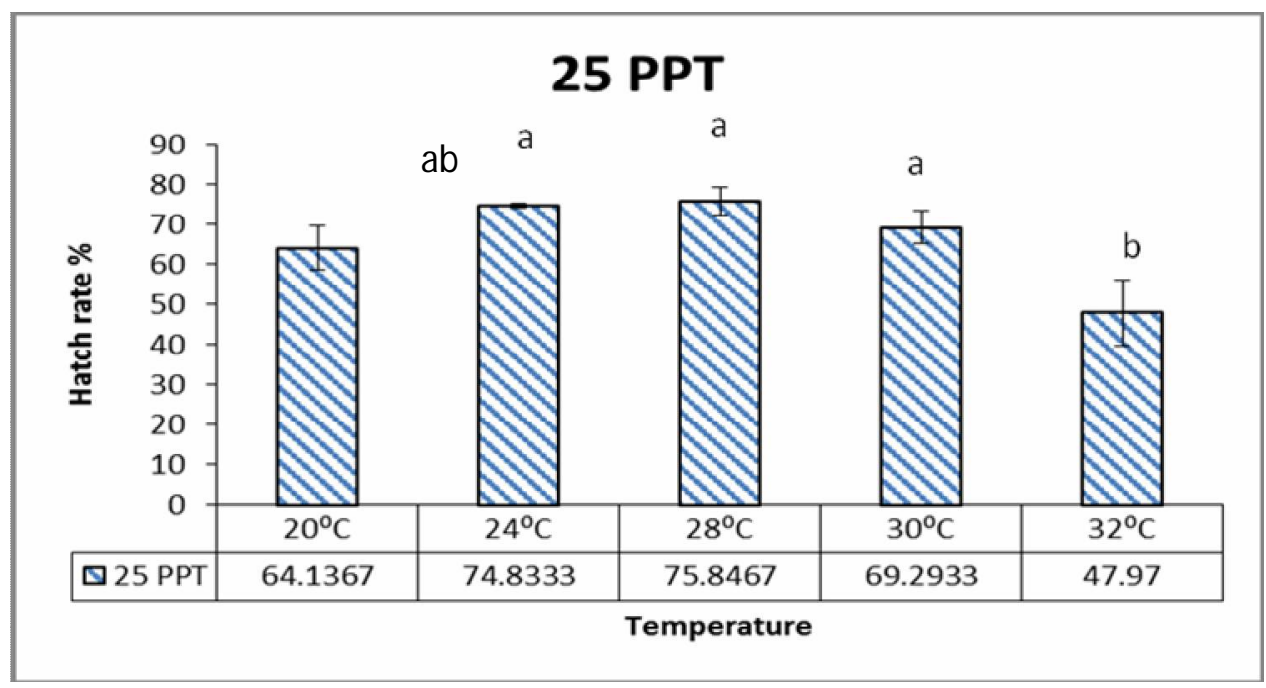

Fig. 2. Effect of temperature on decapsulation of Artemia cyst at $25 \mathrm{ppt}$ salinity. Data as mean \pm sem. Bar with different letters represent significantly difference $(\mathrm{p}<0.05$, analyzed by one way ANOVA followed by Tukey`s test).

Rajkumar and Babu (2015) recorded $72 \%$ hatching rate at 25 ppt salinity. They also observed different hatching rate at different temperature. Highest hatching rate $(88 \%)$ was obtained at $29^{\circ} \mathrm{C}$ and lowest hatching rate $(28 \%)$ at $20^{\circ} \mathrm{C}$ temperature.

Maximum hatching rate $74.45 \pm 0.83 \%$ was found in $28^{\circ} \mathrm{C}$ temperature at 28 ppt salinity. Lowest hatching rate $46.21 \pm 8.18 \%$ in $32^{\circ} \mathrm{C}$ temperature at $28 \mathrm{ppt}$ salinity (Fig. 3). There was no significant difference among $20,24,28$ and $30^{\circ} \mathrm{C}$ $(\mathrm{p}>0.05)$.

Highest hatching rate $89.38 \pm 0.96 \%$ was observed in $24^{\circ} \mathrm{C}$ temperature at $30 \mathrm{ppt}$ salinity and lowest hatching rate $39.58 \pm 10.12 \%$ was found at $32^{\circ} \mathrm{C}$ temperature in $30 \mathrm{ppt}$ salinity (Fig. 4). Significantly lowest hatching rate was found in $32^{\circ} \mathrm{C}$ when compared with 20,24 and $28^{\circ} \mathrm{C}$. There was no significant difference among $20,24,28$ and $30^{\circ} \mathrm{C}(\mathrm{p}>0.05)$. 
An experiment was conducted by Rajkumar and Babu (2015) on the influence of salinity and temperature on the growth of Artemia. They observed 84 and $87 \%$ hatching rate of Artemia cyst at 28 and 30 ppt salinities respectively. But higher hatching rate $(89.38 \pm 0.96 \%)$ was found in this study at $24^{\circ} \mathrm{C}$ temperature. Wansonga and Olendi (2017) found $84.11 \%$ hatching rate at $28 \mathrm{ppt}$ salinity in $28^{\circ} \mathrm{C}$ temperature. Highest $(58.7 \pm 1.5 \%)$ and lowest $(45.7 \pm 3.5 \%)$ hatching rate were calculated at $30 \mathrm{ppt}$ salinity after 36 hours of incubation (Ahmed et al. 1997).

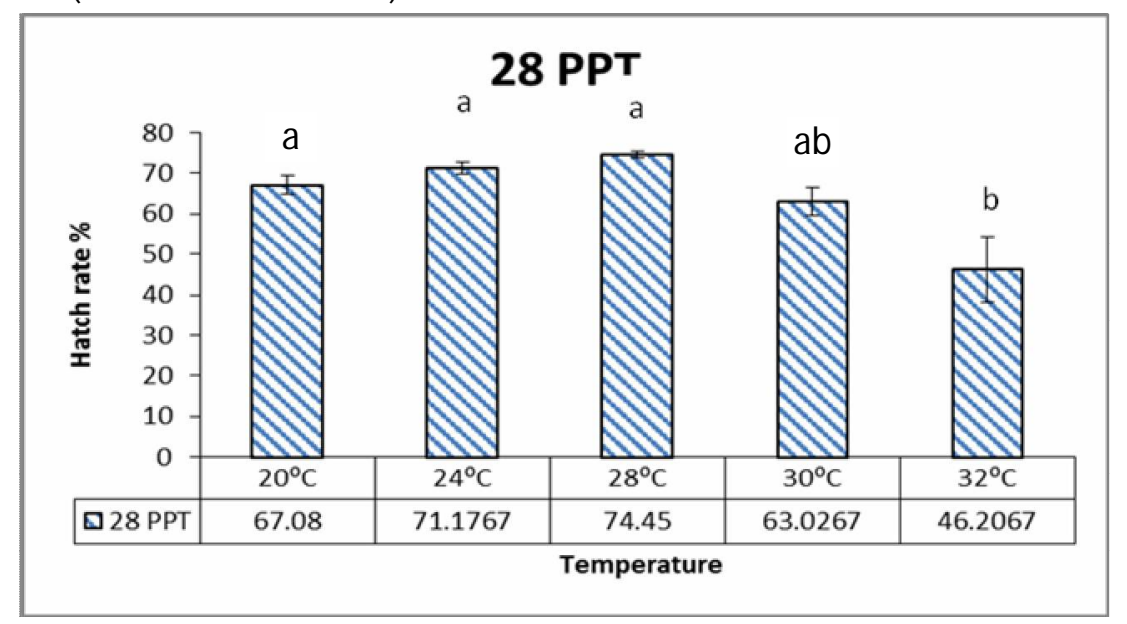

Fig. 3. Effect of temperature on decapsulation of Artemia cyst at $28 \mathrm{ppt}$ salinity. Data are recorded as mean \pm SEM. Bar with dissimilar letters designated significantly difference $(p<0.05$, analyzed by one way ANOVA and Tukey`s test).

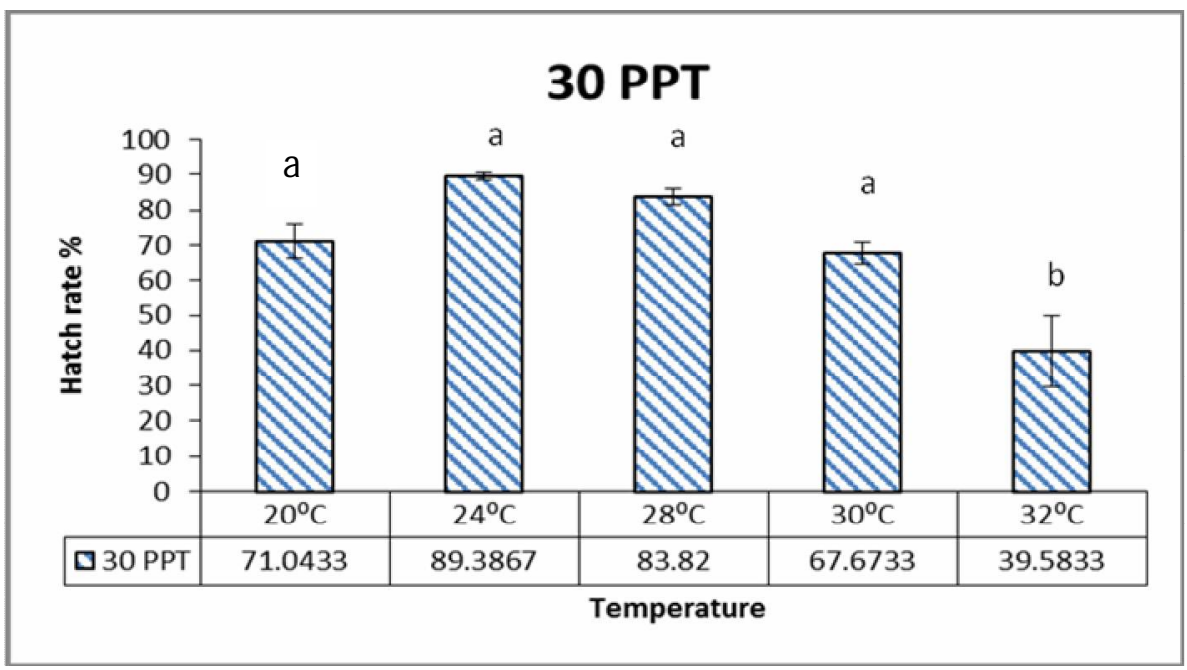

Fig. 4. Effect of temperature on decapsulation of Artemia cyst at $30 \mathrm{ppt}$ salinity. Data are recorded as mean \pm SEM. Bar with different letters specified significantly difference $(\mathrm{p}<0.05$, analyzed by one way ANOVA and Tukey`s test). 
Significantly highest hatching rate $76.46 \pm 4.63 \%$ was found in $24^{\circ} \mathrm{C}$ temperature at $32 \mathrm{ppt}$ salinity and lowest hatching rate $47.36 \pm 7.04 \%$ was found in $32^{\circ} \mathrm{C}$ temperature at $32 \mathrm{ppt}$ salinity (Fig. 5). There was no significant difference among $20,24,28$ and $30^{\circ} \mathrm{C}(\mathrm{p}>0.05)$.

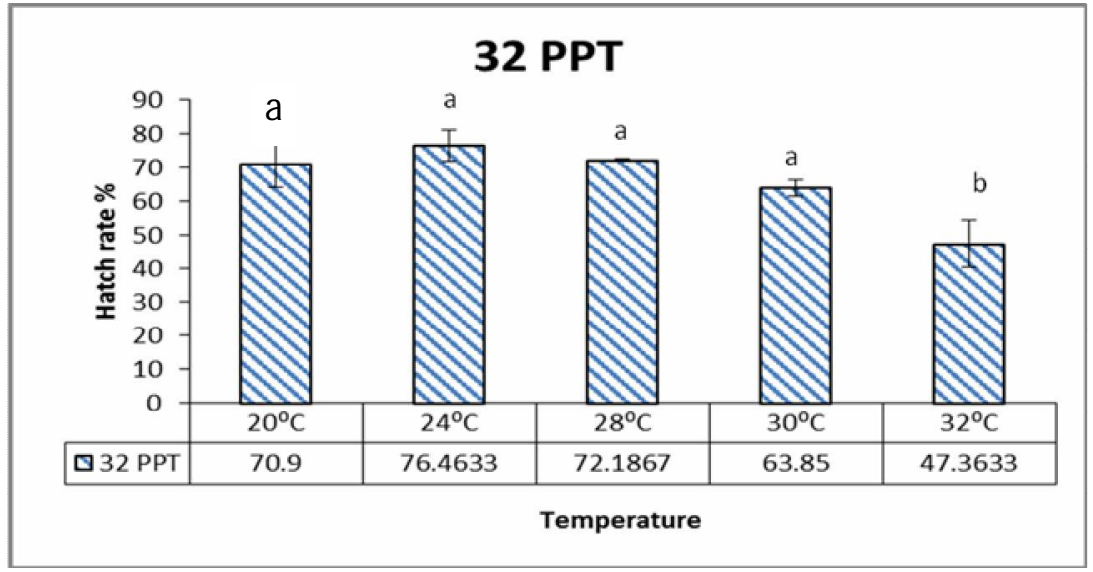

Fig. 5. Effect of temperature on decapsulation of Artemia cyst at $32 \mathrm{ppt}$ salinity. Data are recorded as mean \pm SEM. Bar with different letter show significantly difference $(\mathrm{p}<0.05$, analyzed by one way ANOVA and Tukey`s test).

Here, maximum hatching rate $70.58 \pm 9.5 \%$ was observed in $24^{\circ} \mathrm{C}$ temperature at $35 \mathrm{ppt}$ salinity and lowest hatching rate $25.86 \pm 8.10 \%$ was found in $32^{\circ} \mathrm{C}$ temperature at $20 \mathrm{ppt}$ salinity. Significantly lowest hatching rate was found in $32^{\circ} \mathrm{C}$ at $35 \mathrm{ppt}$ (Fig. 6). There was no significant difference among $20,24,28$ and $30^{\circ} \mathrm{C}(\mathrm{p}>0.05)$.

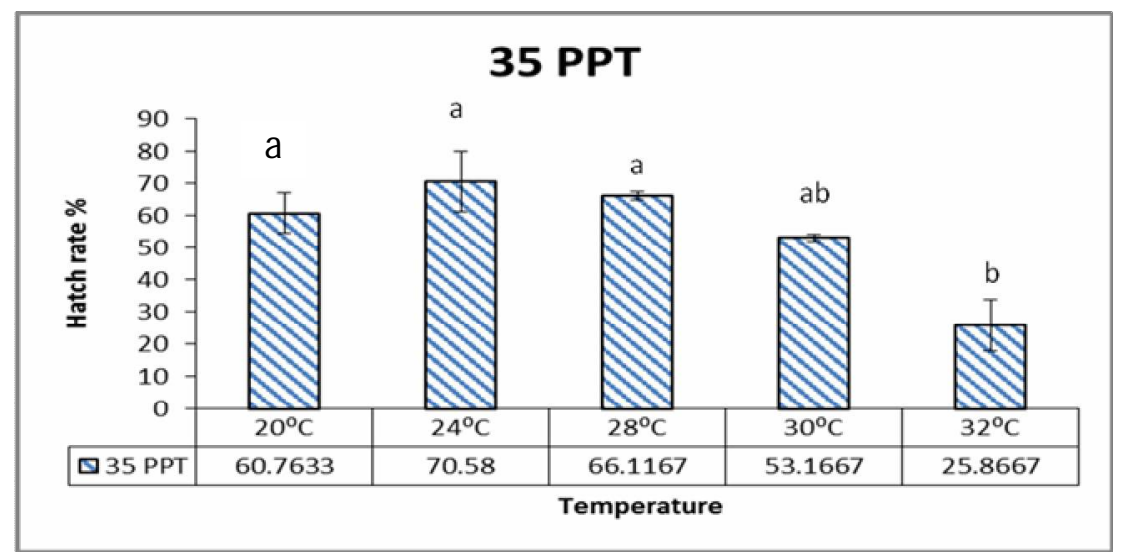

Fig. 6. Effect of temperature on decapsulation of Artemia cyst at $35 \mathrm{ppt}$ salinity. Data are recorded as mean \pm SEM. Bar with diverse letters directed significantly difference $(p<0.05$, analyzed by one way ANOVA and Tukey's test). 
Significantly maximum hatching rate $69.17 \pm 0.70 \%$ was found in $28^{\circ} \mathrm{C}$ temperature at $40 \mathrm{ppt}$ and lowest hatching rate $20.57 \pm 2.71 \%$ was found in $32^{\circ} \mathrm{C}$ temperature at $40 \mathrm{ppt}$ salinity (Fig. 7). There was no significant difference between 30 and $32^{\circ} \mathrm{C}$ and among $20,24,28$ and $32^{\circ} \mathrm{C}(\mathrm{p}<0.05)$. But significantly highest hatching rate was observed in 20,24, 28 compared with 30 and $32^{\circ} \mathrm{C}$ at $40 \mathrm{ppt}$.

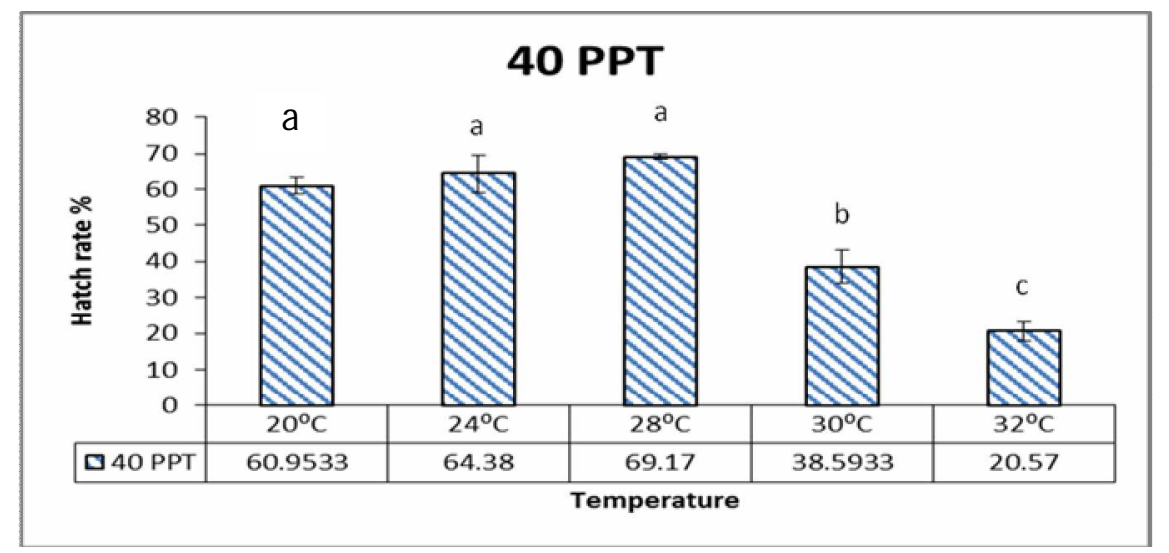

Fig. 7. Effect of temperature on decapsulation of Artemia cyst at $40 \mathrm{ppt}$ salinity. Data are recorded as mean \pm sem. Bar with different letters pointed out significantly difference $(p<0.05$, analyzed by one way ANOVA and Tukey's Test).

Sorgeloos and Skujlasekarapandian (1984) suggested 35 ppt salinity of sea water is ideal for Artemia cyst decapsulation in laboratory condition. But Rajkumar and Babu (2015) found 75 and 58\% hatching rate at 32 and 35 ppt salinity respectively. Ahmed et al. (1997) recorded maximum (47.7 $\pm 2.1 \%$ ) hatching rate and minimun $(40.3 \pm 1.2 \%)$ at $40 \mathrm{ppt}$ salinity for processed and preserved cyst whereas Wansonga and Olendi (2017) observed 89.88\% hatching rate at $40 \mathrm{ppt}$ salinity. But this result did not match properly with the previous literature.

Generally, Artemia cyst decapsulation depends on many factors like temperature, salinity, pH, cyst quality, aeration etc. Moreover, fixed temperature, cyst density and container's design also play important role in maximal production of Artemia cyst (Lavens and Sorgeloos 1996, Sharahi and Zarei 2016). The variation of Artemia decapsulation rate in different literature could be the effect of different above mentioned factors.

It can be concluded from the above discussion and the findings of this study that the decapsulation rate of Artemia cyst greatly depends on salinity and temperature. This result, $30 \mathrm{ppt}$ salinity and $24^{\circ} \mathrm{C}$ temperature could be the best 
combination of higher rate of decapsulation of Artemia cyst. Moreover, decapsulation rate decreases above $35 \mathrm{ppt}$ salinity and $30^{\circ} \mathrm{C}$ temperature.

Acknowledgements: This research work was financially supported by the University Grants Commission of Bangladesh.

\section{LITERATURE CITED}

AHMED, S.U., RAHMAN, M.A., ISLAM, M.N. and KAMAL, M. 1997. Effect of decapsulation on viability and hatching performance of Artemia cysts at different salinity levels. Bangladesh Fish. Res. 1(2): 67-7 4.

LAVENS, P., TACKAERT, W. and SORGElOOS, P. 1986 International study on Artemia. XLI. Influence of culture conditions and specific diapause deactivation methods on the hatchability of Artemia cysts produced in a standard culture system. Mar. Ecol. Prog. Ser. 31: 197-203.

NASER, N.M., HASAN R., NIPA S.A. and RASHID H.A. 2016. The Prospect and Feasibility Assessment of Brine Shrimp (Artemia franciscana) Culture in Bangladesh. Journal of Environmental Science and Engineering 5: 261-267.

LAVENS, P. and SORGELOOS, P. 1996. Manual on the production and use of live food for aquaculture FAO Fisheries Technical Paper. No. 361. Rome, FAO. 295 pp.

SHARAHI, A.R. and ZAREI, S. 2016. Mutual effect of light and turbidity on hatching of Artemia franciscana cysts. International Journal of Fauna and Biological Studies 3(2): 03-06.

SORGEloOS, P., DHERT, P. and CANDREVA, P. 2001. Use of the brine shrimp, Artemia spp. in marine fish larviculture. Aquaculture 200: 147-159.

SORGELOOS, P. and SKUJLASEKARAPANDIAN, S. 1984. Production and use of Artemia in aquaculture. CMFRI Special Publication Number 15: 26 pp.

RAJKUMAR, G. and BABU D.E. 2015. Effect of light, temperature and salinity on the growth of Artemia. International J. Engineering Science Invention. 4(12): 7-14.

TRIANTAPHYLlidis, G., ABATZOPOUlOS, T. and SORGELOOS, P. 1998. Review of the biogeography of the genus Artemia (Crustacea, Anostraca). J. Biogeography 25(2): 213-226.

WANSONGA, G.A. and OLENDI, R. 2017. Effect of different salinities on the hatchability and the survival of brine shrimp, Artemia Salina from malindi, Kenya. African Journal of Education, Science and Technology 3(4): 1-5. 